\title{
Applying Service Design Thinking Techniques for the Construction of a Service to Capture Informal Learning Activities in Distance Education
}

\author{
Ivanildo José de Melo Filho, Luma da Rocha Seixas, Rosangela Maria de Melo, Alex Sandro Gomes \\ Federal Institute of Pernambuco (IFPE) \\ Paulista Campus - Brazil
}

\begin{abstract}
This article aims to present the results of the design and development of the service to follow-up formatively from informal learning activities to online courses based on LMS environments applying Service Design Thinking Techniques as a methodological strategy. This one is composed by 04 (four) steps: Exploration, Creation. Reflection and Implementation. In the Exploration stage, the entire process had 72 teachers and tutors from different Universities and Federal Institutes in Brazil. At the Creation stage, online questionnaires were used with these participants to understand their perceptions about what informal learning resources are used by learners. The stages of Reflection and Implementation allowed to establish functional requirements for the development of the service, and also allowed to generate the prototypes for the proposed service. The service was evaluated by 6 experts who produced new evidences to improve service development and the next steps of the research are focused on the possibilities and restrictions to integrate it with the different LMS environments and define what development architecture will be used.
\end{abstract}

\section{Introduction}

The studies of [1], [2] and [3] reinforce the need that, in addition to the interaction of the learner with the resources, it is also necessary to consider the environment in which it is inserted in order to provide different possibilities of interaction. This action must be continuous, in the same way that it must be adapted in a transparent way to the context in which the student is inserted. This is linked to the fact that advances in technologies, dissemination of distance learning at the most different levels, access to information can be done in various ways anywhere through different devices and immediately. In this direction, when considering these aspects, the elements or mechanisms involved can be used as tools that enable and potentiate the learning process.

About learning in the distance learning modality, it is known that the adoption of this modality is accomplished through the use of Learning Management Systems (LMS), through which the learner has access to content and activities, planned, developed and made available exclusively in the environment, which are usually accessed, from the internet. Due to this, it is restricted to the performance of its activities only in the institutional environment. On the other hand, the use of this type of environment in the modalities of distance learning or face-to-face has a series of resources at its disposal aiming to provide teaching and learning with more diversity to students. This is because their use and familiarization allow them to explore their opportunities for collaboration and engagement of learners in a variety of ways. The use of this type of environment for training is limited considering that all the knowledge and activities associated with the intended training are now confined to a specific environment [4] [5] [6].

These follow a similar philosophy for student follow-up on courses that are conducted in these environments. This intrinsic limitation to LMS has been discussed since 2001 when [7] have shown that LMS-based architectures do not fully meet the lifelong learning needs of students, preventing them from managing their learning. Furthermore, these architectures are not adequate to provide learners with continuity, even if temporary, when they are disconnected from these environments. In addition, the LMS are mainly tools to deliver and organize content "manufactured" by the teacher for a course, placing students in a passive role as followers of modules of a course at a pre-determined.

Efforts have been made so that a variety of educational resources are made available to teachers, tutors and students for individual or collective use aiming at the autonomy of those involved in the process. This variety of possibilities is available for individuals to create, discard and redo their profiles, as well as their way of identifying themselves in these environments. It is known that a user with sufficient technical skills to use the Internet can have more than one email account, profiles on different social networks, YouTube video channel, share documents, create blogs, collect photo albums, may also be enrolled in several courses in different educational institutions, using different LMS, among other possibilities.

This research aims to present the results of the development of the interfaces for a service of formative accompaniment of informal learning activities for courses based on LMS environments. The other sections that are part of this work are described below: Section 02 discusses the 
importance of informal learning activities. Section 03 characterizes the personal learning environments as important tools to support the achievement of the informal activities of the learners. Following, section 04 presents the importance of "accompaniment" these learning activities and distinguishes their reaction with the "monitoring" action present in the LMS. Section 5 highlights a recent study on a validated conceptual proposal for capturing informal activities in LMS-based courses. The method used is described in section 06 where the use of Service Design Thinking as a strategy is justified. As results of the process, section 07 presents the developed prototypes and section 08 presents some evaluation results. Finally, Section 9 concludes with the final considerations and the next steps to be taken in the research.

\section{Informal Learning Activities}

Informal learning activities are a phenomenon naturally present in people's daily lives. With the passing of the last decade, it is now possible to identify that the learning activities supported by technologies have fulfilled their role in the different modalities of teaching, be they: face-to-face, distance or hybrid teaching when using Learning Management Systems (LMS). Regardless of the modality, a present challenge to be faced by coordinators, teachers or tutors is closely related in how to integrate informal learning activities in the process of conducting a course or discipline. In particular, in the didactic situations where virtual learning environments are used a present problem is always emphasized by the literature: the difficulty of perceiving and accompanying the learners in their various learning activities that are carried out (informally) from these environments, especially when the apprentices use different types of tools, also characterized as Personal Learning Environments (PLE).

The author [8] points out that informal learning has received increasing attention because of its relationship with lifelong learning. It can be reflected as learning that occurs in the school environment, at work or experimentally. In particular, the author warns that this happens when individuals begin to make sense of the experiences that arise during their daily activities.

According with [9], the informal learning results from activities of daily living related to work, family or leisure. By nature, it is not structured in terms of learning objectives, learning time or learning support and typically does not lead to certification. Informal learning may be intentional, but in most cases it is unintentional or incidental or random. [10] considers informal learning as any learning or collaboration that occurs outside a classroom, seminar or workshop, beyond the scope of a self-study course, and away from any recognized environment as part of formal learning. The author draws attention to informal learning in the sense that it occurs as a result of interactions between individuals. And, often, it is not recognized as learning because many of these interactions are considered to be an exchange of knowledge gained throughout life.

In [11] is described that even in formal learning, individuals learn informally, especially in the communities in which they participate and in their belief systems. In addition, this reiterates that in this type of learning is not only positioned in contextualized knowledge and technical skills. On the contrary, through informal learning it is possible to acquire a set of values and at the same time be socialized in a particular culture. The author calls this aspect of hidden curriculum since these actions allow the direction of actions to be pursued by them.

\section{Personal Learning Environments (PLE)}

According to [12] personal learning environments are single-user e-learning systems that provide access to a variety of learning resources and can also provide access to learners and teachers who use others PLE or LMS. The author highlights three (3) motivations that are associated with the design of PLE and are described below: (1) The needs of learners throughout their lives for a learning environment that provides a standard interface for different institutions, and also allows the information portfolio to be maintained between them; (2) Need to provide answers to pedagogical approaches assimilate, understand and reflect - where learners who use learning environments may be under the control of their own learning and (3) Finally, the needs of learners who sometimes perform learning activities outside the virtual environment.

The concept of the personal learning environment has emerged in recent years through the work of online theorists, researchers and developers. This emergence is the result of: (1) the limitations experienced by administrators, trainers, teachers and students using LMS, and (2) recognition of the importance of informal learning and lifelong learning in all their domains.

The Author [13] states that each individual is a unique being and that individuals can share common points of view, but lately the learners experience the world in an idiosyncratic way, and each brings its uniqueness in every situation they encounter, especially in this digital age. For the author, this limiting scenario of the LMS allows to say that the PLE can be characterized as spaces where learners seek different forms of interaction and build their own learning paths. 


\section{Formative Accompaniment For Informal Learning Activities}

The term formative accompaniment derives from the concept of formative assessment as defined by [14] and differs from the term "monitoring learning" found in the literature. In spite of being almost synonymous, the term "monitoring learning" suggests the observation of a certain phenomenon, in a period of time with the objective of verifying that the established conditions are within the standards, according to [15]. The term is consistent with [16] and aims to bring proximity to the phenomenon to be observed, in the sense of being together, to provide assistance, to guide, give direction, to customize this support throughout the execution of the process in training courses in the distance modality, mainly in the capture and integration of informal activities of learning to the formal learning environments. Allowing, when possible, that these activities can be incorporated into the formative assessment process.

\section{Service For Formative Accompaniment To Capture Informal Learning Activities}

The author [17] states that a service proposal in its essence should seek to provide a collection of capabilities, where these can be grouped because they relate to a functional context established by it. Thus, the creation of the conceptual model of the service was originated by several discussions, mainly with a view to ensuring compliance with the following points:

a) Allow teachers and tutors to select and configure their preferences regarding their classes and disciplines.

b) The difficulties related to interoperability, integration of activities, traceability, execution of single-sign-on and security are considered.

c) Capture learners' information when they use the most different tools that make up their personal learning environment.

d) The selection of the integration scenario adheres to the service proposal. To provide teachers and tutors with indications of follow-up activities outside LMS according to their preferences, allowing them to be integrated or considered in the evaluation process of a course or discipline.

The conceptual diagram specified by [16] details the service for the formative accompaniment the informal learning activities in its conception combines the conceptual characteristics of the LMS and others personal tools, as well as the operational ones described by [18] when it refers to the opening of the LMS in the offer of support to implementations of specifications interoperability with other technologies, as it is shown Figure 1.
Indications "1" and " 3 " refer to the educational contexts PLE and LMS. The indication "1" refers to the formal educational environments, or also called institutional environments. In the proposed scenario, the service considers that an institution may have one or more LMSs in operation. The indication "3" refers to the context in which the PLEs may be inserted. In this case, they are represented by the web resources, as well as by mobile devices.

The indication "2" represents the learning analytics scenario for the formative accompaniment and is composed of 4 (fourth) stages. It is the core of the service and has the mission of ascertaining in depth what information will become important in this process of capturing informal learning activities.

\section{Method}

The choice of Service Design Thinking based [20] as the methodology used in this research is due to the fact that this is an interdisciplinary approach that combines different methods and tools from different disciplines. It is a new way of thinking, not an academic, autonomous discipline. (Stickdorm and Scheider, 2014, p.31). The service design approach allows us to rewind, reflect and, if necessary, re-start processes based on the lessons learned from the previous phase. The authors say: One of the key features of service design thinking is that this approach is not intended to avoid errors, but to exploit as many errors as possible.

The decision to adopt the methodological process to use the recommendations of the Thinking service design for the capture of informal activities in distance education emerged from the identification of difficulties or needs among teachers, tutors related to the alignment of informal learning activities in environments formal education using e-learning systems. A definition of services presented in [20] states that: Services are a series of interactions between users and the service system, through many different points of contact throughout the user's journey. As it is a service design, this step will consider for the development of the evidence found in the literature review, as well as the use of an interdisciplinary approach that may be based on the paradigm of service design thinking. Therefore, this article specifies the development and construction of a service to capture informal learning activities in courses or disciplines supported by LMS environments.

Using the Service Design Thinking techniques described by [20] composed of 04 stages (See Figure 2) namely: Exploration, Creation. Reflection and Implementation. The relationship of these stages was scaled as follows. In the Exploration Stage the objective was to have a clear understanding from the perspective of the users in order to understand the phenomenon to be explored, highlighting problems, 


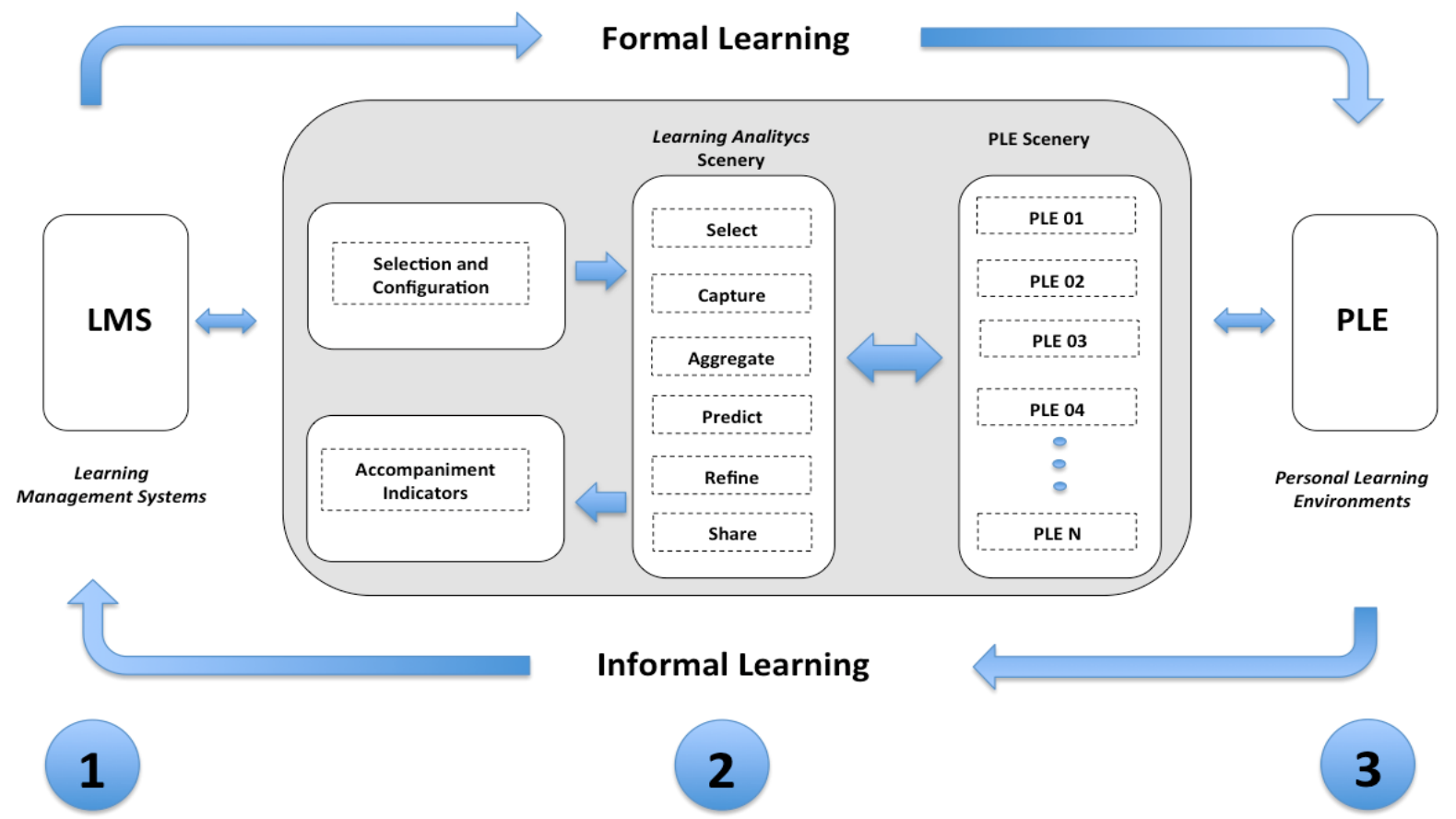

Figure 1. Conceptual Diagram for the Accompaniment of Informal Learning Activities [16]; [19]

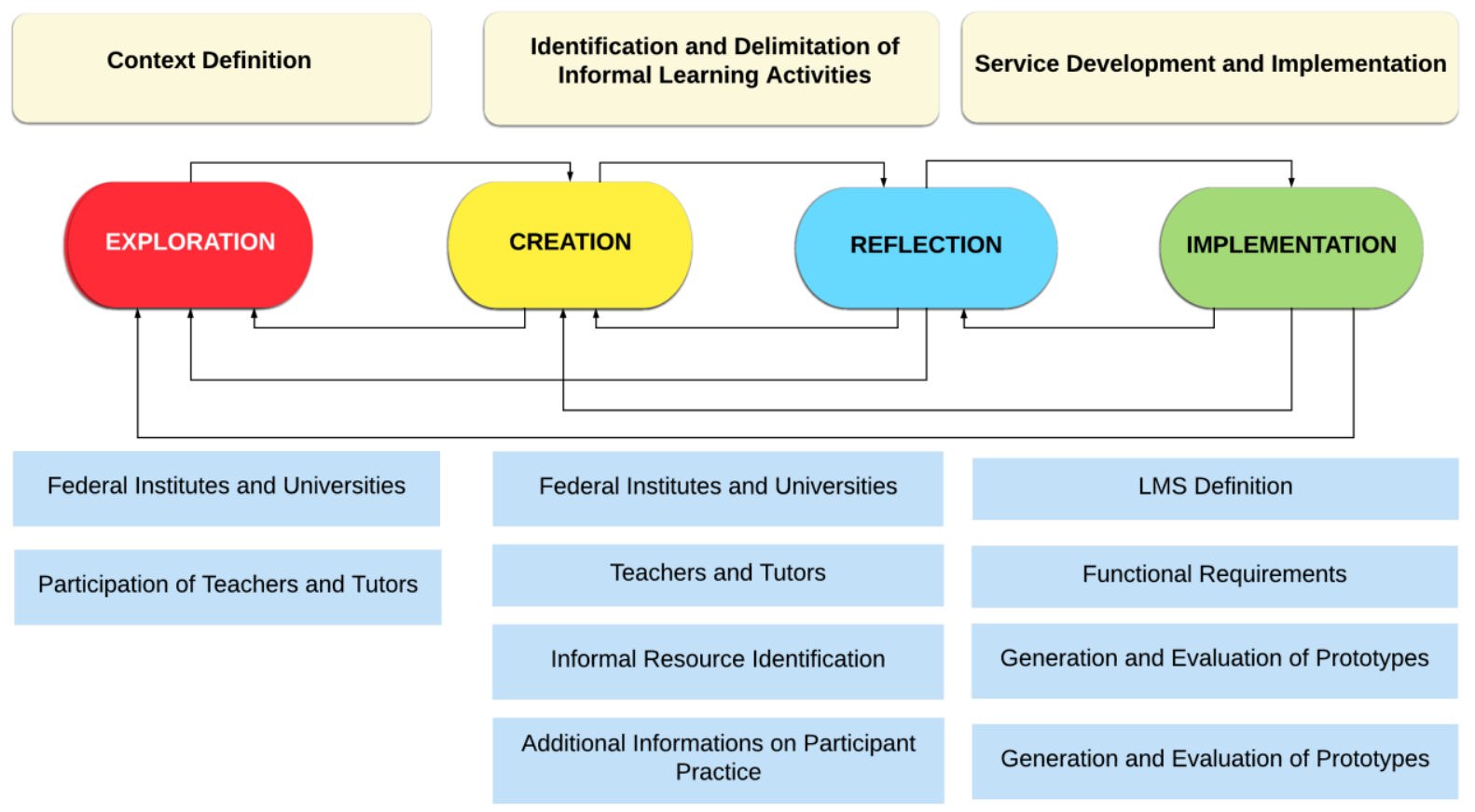

Figure 2. Relationship among the Stages and the Activities of Service Design Thinking 
needs, motivations and expectations. In the Creation Stage, a crucial point is to learn as much as possible before taking any action on its development, testing ideas and concepts captured from the exploratory activity. It is the stage of the embryonic in the iterative process being closely related to the activity of reflection. With regard to the Reflection Stage, this stage has as its challenge to deal with the intangibility that a service brings in itself, for this reason to position it in the context of actual use, or in circumstances close to your daily life, produce the return which allow us to deliver and evolve the service over time. Finally, the Implementation Stage in this purpose is to make real service, concrete and coherent service based on the results or inputs of previous activities.

The method used was centered in three topics: i) identification and delimitation of the informal learning activities; ii) specification of the service requests and; iii) selection of the LMS to be used. The procedure had the goal to perform a selection about what informal activities would be considered for this research and what type of tools would be the most used from the point of view of the answerers. The participants were 72 teachers and tutors from different educational institutions in Brazil participated in the research and they were all invited to answer an online questionnaire composed by 13 questions.

This instrument had the objective of registering and understanding in a comprehensive way how the activities proposed in the LMS environment are seen, as well as what informal learning instruments and activities are recognized and used by them. The questions that constituted the questionnaire were centered in 1) Identify the profile of the respondent and his or her experience with distance education or courses based on the use of LMS. 2) Check how the evaluation of apprentices in the courses is carried out. 3) Obtain the general perception of teachers and tutors about the execution of activities within the virtual environment (LMS). 4) Collect the different perceptions of the different perceptions of teachers and tutors on the activities of environmental learners. 5) Identify how teachers and tutors understand and relate learners' learning experiences while performing a course or course in the LMS. 6) Find out whether teachers and tutors identify other types of resources or devices for learners to carry out their activities. 7) Identify which tool is the most frequently perceived by teachers and tutors in which learners make more use outside the LMS environment. 8) Understand if teachers and tutors identify and support learning activities outside the virtual environment, considering that the evaluation process in this modality uses the formative assessment paradigm. 9) Verify if the perception of the teachers and tutors on perceiving the activities of the apprentices outside the LMS environment can serve as support to the formative assessment process. From the results, the requirements were specified based on their informal preferences.

\subsection{LMS Candidates Selection}

The selection of the LMS candidates considered mainly those environments that have acting developing communities and that are open source. The following LMS environments were analyzed: Amadeus

LMS $<$ https://softwarepublico.gov.br/social/profile/amade us>, Moodle <https://moodle.org/> and Openredu $<$ http://openredu.cin.ufpe.br/>.

Among the candidates' environments, the Openredu LMS was chosen for development, integrating it with the service proposed on this research. The reasons that motivated its choice were related to its modular architecture, under which the LMS was developed, allowing the communication process among the requests previously established with its architecture to be supportive to its implementation. The Amadeus LMS and Moodle environments were removed from the selection due to its restrictions of integration with other environments.

\subsection{Perspectives of the Learners about the Activities outside the LMS}

The answerers clearly noticed that the activities in the LMS helped them to go deeper in the proposed themes, despite allowing the visualization of the themes in different ways. On the other hand, part of them pointed out that the activities seem excessive, compromising their conclusion in the established deadlines. They complemented the existence of divergences between the content available and the activities proposed by the teachers. They also revealed that their actions on the activities of the LMS are not confined in the LMS. So, they also revealed that their actions on the activities of the LMS were not confined in them.

Most of the answerers affirmed they seek the themes proposed in the LMS activities in other means. In order to do so, they use different tools informally. On their answers it was possible to notice that YouTube and Facebook were the favorite tools. When asked about how they notice that learning activities performed outside the LMS could contribute on the assessment process of a discipline or course, most of the answerers signaled that this possibility could be an additional resource to be considered and could help in the accompaniment of the performance of the activities contained in the LMS, besides allowing them to direct and organize their activities aligned to those proposed in the LMS. 


\subsection{Requirements Established for the Development of the Service}

The preliminary requests proposed are derived from stages that compose the conceptual model of the service and consider the research problem specified in the introduction of this article. Considering the information available by the Application Programming Interface (API) of favorite tools by the learners; when on Facebook: information about the user profiles, events selected by the users, groups the users are part of and pages liked by the users; when on YouTube: videos commented by the users, marked as favorites, shared and liked. The available information allowed the specification of the requests to be in consonance with the objective proposed by this investigation. From the results of the answers of the participants and aligned to the stages recommended in the model proposed by [17], 26 Functional Requirements (FR) were established for the proposed service, as presented on Table 1.

\section{Prototypes}

The prototypes designed for the service are going to be presented. Some considerations were evaluated, especially about how the service would work. The suggestion of conception of the prototype considered that the actions of the learners in the interaction with the accompaniment service should be the minimum possible, only guaranteeing them the autonomy to decide to be accompanied or not. This decision preserves its privacy and avoids the teacher to receive future inquiries.

Due to natural limitations of the LMS to interoperate with other environments, it has been decided that the service would work independently from the LMS (see Figure 3) and open to multiple connections with other LMS. The communication between the capture services and the LMSs would be centered in the updates of the information on the groups, learners and alert messages sent to the groups selected for accompaniment (see Figure 4 and 5).

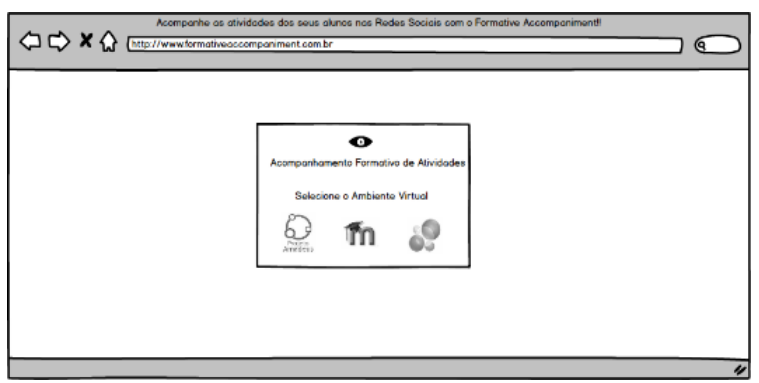

Figure 3. Login Interface

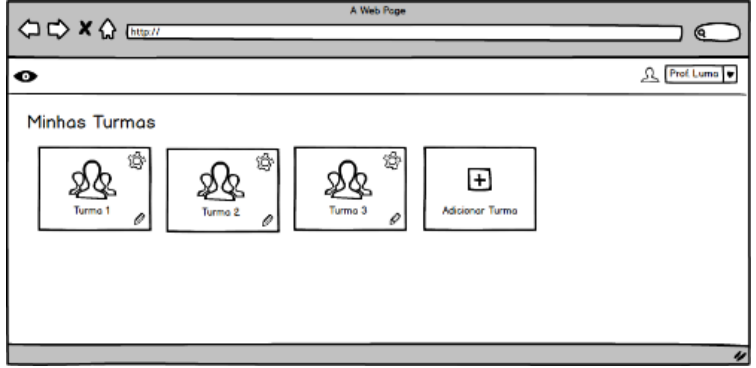

Figure 4. Classroom Selection for Accompaniment

The settings about what will be captured consider the records of the keywords in the LMS that will be exported for the service, and it is possible to edit them if the teacher wants to. The prototype represented by Figure 6 exemplifies the import of keywords of a hypothetical course of "Objectoriented Programming", existing in the LMS Openredu that were imported for the Service. In the example, the imported keywords were: "Programming, "Heritage", "Polimorfism" and "Java". Once imported, the proposed prototype allows that at this moment, both teacher and tutor can modify or exclude them in case they want to. Regarding the settings about what the tools can capture of informal activities, the prototype represented by Figure 5 presents the possibility of the teacher to configure what types of activities can be captured.

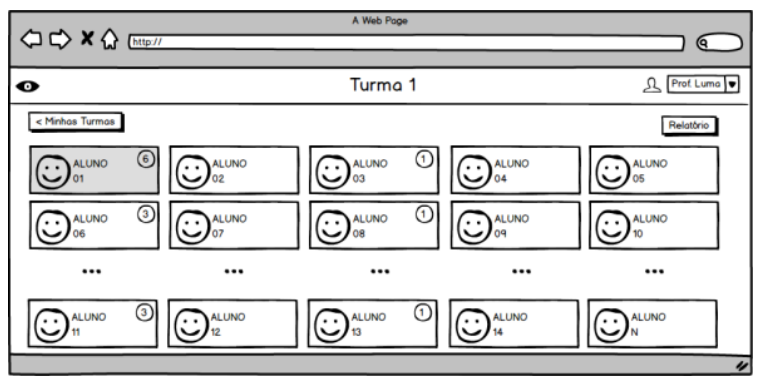

Figure 5. Learners from Specific Discipline

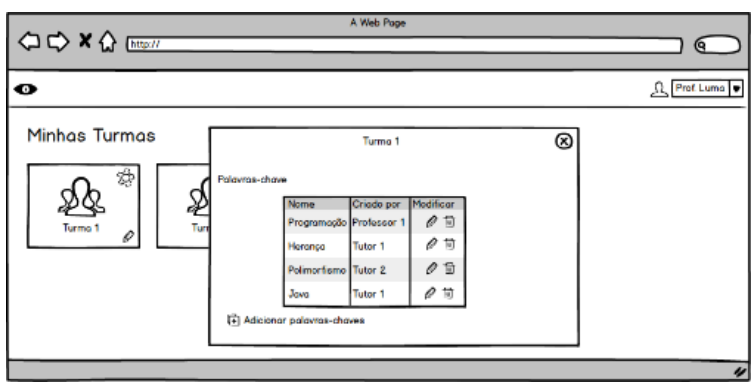

Figure 6. Configuring Capture

During the process of conceiving the prototypes of the interfaces, we have prioritized the capture design 
of YouTube, Facebook and Twitter only, since the actions to be captured on these tools contain similarities. In the prototype, YouTube was the informal context selected for the configuration - the teacher can select if he wants to receive the comments, which videos were marked as favorites (see Figure 7 and 8) which were liked and shared.

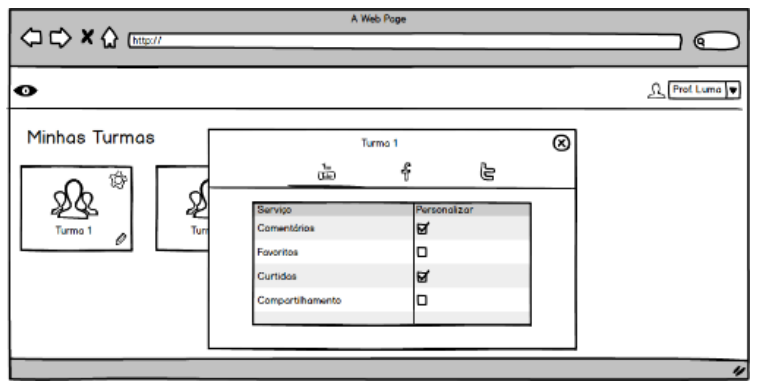

Figure 7. Configuring YouTube Capture

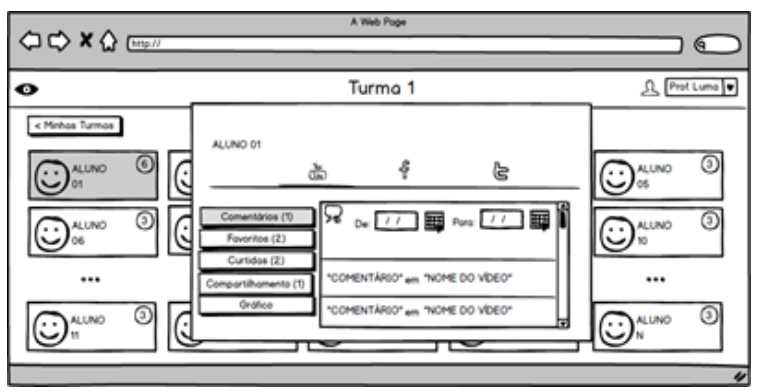

Figure 8. Visualizing Selected Activities

\section{Prototypes Preliminary Evaluation}

It is emphasized by [18] that the evaluation of design using low fidelity prototypes allows the evaluator to perform with the users an evaluation, being able to compare with other design possibilities. The Prototypes Evaluation Process was conducted according Figure 9.

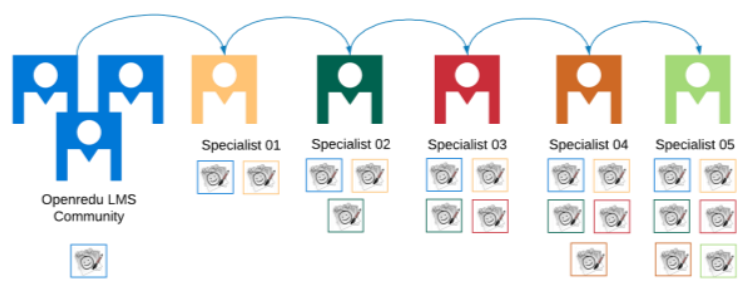

Figure 9. Prototypes Evaluation Process

The resulting prototypes were evaluated in (06) six different times: 03 evaluation rounds with 03 collaborators of the LMS Openredu Community and 5 experts in the field incrementally, without excluding the contributions that preceded and preceded each evaluator specialist.
The first moment started with the Openredu Community, the reason for the choice was due to the fact that the selected environment is managed by this group. All evaluation moments were, as mentioned, incremental and were governed from the perspective of framing, refinement and discovery of possibilities for the design of the proposed service. The evaluation allowed to elucidate possible inconsistencies and refinement of the preliminary requirements, contributing to the generation of new prototypes and to the definition of the architecture of the service.

The evaluation script was sequential and incremental all relevant information related to the prototypes generated by each specialist were recorded. The evaluation process consisted of presenting the research problem to each specialist at different times. It was informed to each one the reasons by which to realize the informal activities could help teachers and tutors in the conduction of courses in environments supported by LMS. In addition, it was also presented the process of choosing the LMS environment and informal activities highlighting the tools most voted by the respondents. In addition to the Openredu Community recommendations on interoperability between the service and the LMS.

Among the several points observed by the experts, we highlight the observations made with the prototype represented by Figure 10. They questioned the reason for allowing the tutor to edit the keywords when selecting a class or discipline for follow-up. It has been clarified to specialists that in LMS environments the configuration of a course or discipline is usually an exclusive activity of the teacher or the coordination of the institution when the environment is prepared before starting the course.

In addition, it was pointed out that allowing the tutor through the service to perform this activity in a complementary way to the teacher, would make its action effective, since the actions performed by the tutor according to official rules constitute the first level Interaction between learners and the environment. All agreed with the reasons and stressed that the interface proposal objectively complies with its proposal and does not present any aspect of change to be registered by them.

On the other hand, "Specialist 5" perceived how a strong point to grant the tutor this permission, the same registered that his experience as a tutor was deeply restricted and that the process of tutoring was conditioned to the restrictions recommended by the teacher and by the institution, making its action in the process of tutoring.

The Specialists "4" and "5" suggested incorporating the prototyped functionalities in the two interfaces to be unified in only one interface. 


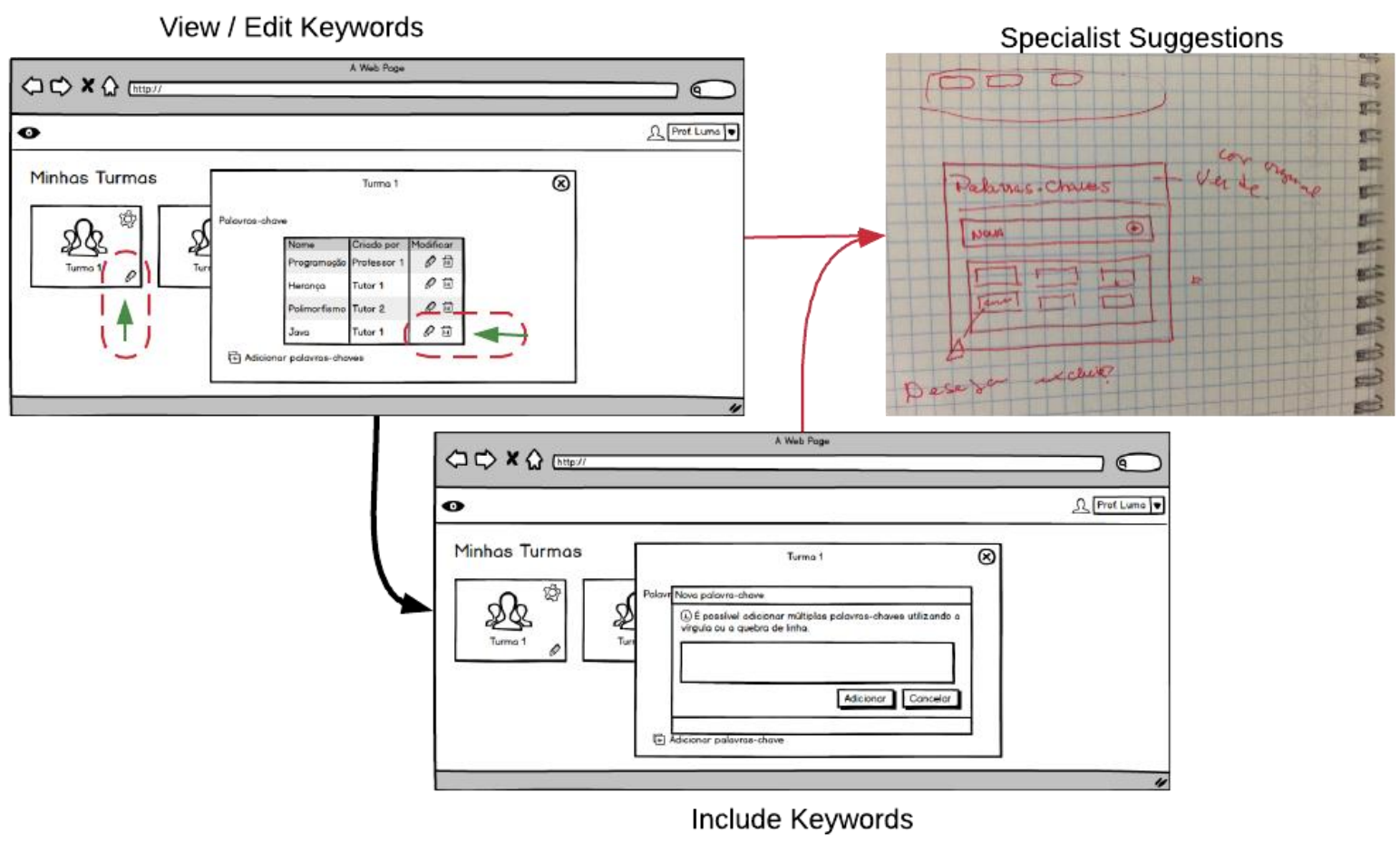

Figure 10. Specialists Suggestions

The Figure 11 shows the paper prototype suggestion of Specialist 5. By means of the specialists' points it was possible to review and redesign two prototypes into a single interface capable of incorporating the desired functionalities.

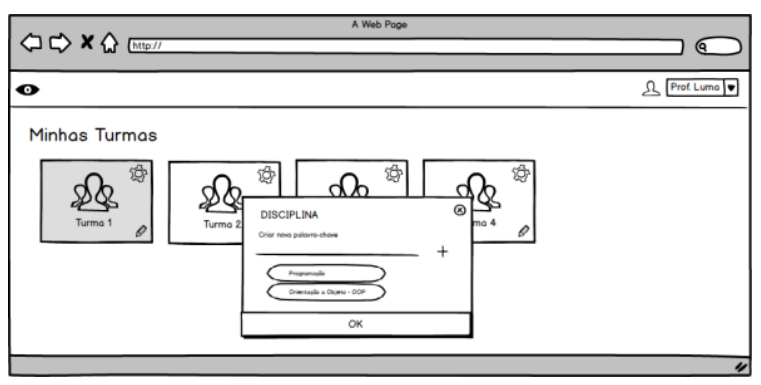

Figure 11. Prototype with the Built-In Suggestions

They questioned why they would allow the tutor to edit the keywords when selecting a classroom or discipline to accompaniment (see Figure 12). It was clarified to specialists that in LMS environments the configuration of a course or discipline is usually an exclusive activity of the teacher or the coordination of the institution when the environment is prepared before starting the course. In addition, it was pointed out that allowing the tutor through the service to perform this activity in a way complementary to the teacher, would make its action effective, since the actions performed by the tutor according to official rules constitute the first level interaction between learners and the environment.
All agreed with the reasons and stressed that the interface proposal objectively complies with its proposal and does not present any aspect of change to be registered by them.

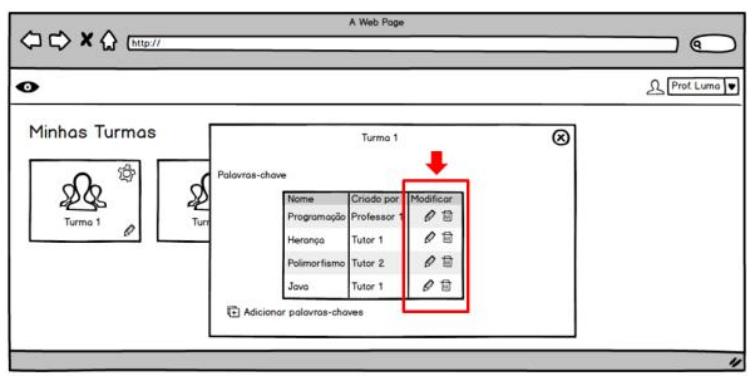

Figure 12. Interface to allow the tutor to edit the keywords when selecting a classroom or discipline

On the other hand, "Specialist 5" perceived how a strong point to grant the tutor this permission, the same registered that his experience as a tutor was deeply restricted and that the process of tutoring was conditioned to the restrictions recommended by the teacher and by the institution, making its action in the process of mentoring.

\section{Considerations and Next Steps}

The specification of the conceptual model was based on the evidences presented by the authors throughout this document considering difficulties or 
inadequacies existing between the integration of LMS with other tools. The requirements presented are results of the evidences identified in the literature and of the questionnaires applied mainly in the reality present in the courses that use LMS environments as support of learning activities.

In relation to the preliminary requirements established, these come from the evidence mentioned by literature, by identifying the massive use of social tools, such as: YouTube, Facebook, Blogs, among others. It is a fact that the API's intrinsic functionality to these tools allows you to collect an enriched range of actions from your users. These actions may characterize possible learning activities outside formal learning environments.

Considering that the preliminary requirements characterize a transitional situation on the proposal of the service and in order to advance in the development of this research. The prototypes generated produce the use experience that teachers need to make informal activities help and guide their actions along with the learners, besides expanding the limiting character of the LMS on this phenomenon.

The following steps that guide this research are directed to evaluation with the community of the Openredu LMS, verifying the possibilities and restrictions to integrate with the environment and define what development architecture will be used. Next, the prototypes will need to be evaluated by experts to investigate the level of communication before the development of its final design. It is important to note that the stages of reflection and implementation still remain in continuous operation. From this cyclical process, in addition to the final result of the interfaces, the service architecture will be developed and implemented.

\section{References}

[1] Goh, T. T., A framework for multiplataform e-learning systems. PhD Thesis. Massey Univertsity. New Zeland. 2007.

[2] Tori, R., "Education without distances" - Interactive technologies in reducing distances in teaching learning. School of the Future - University of São Paulo. Publisher SENAC. São Paulo. 2010.

[3] Ozcelik, E.; Acarturk, C., Reducing the spatial distance between printed and online information sources by means of mobile technology enhances learning: Using 2D barcodes. Computers \& Education, v. 57, n. 3, p. 2077 2085, 2011.

[4] Kats, Y., (Ed.). Learning Management System Technologies and Software Solutions for Online Teaching: Tools and Applications: Tools and Applications. IGI Global, 2010.
[5] Adams, C., Learning Management Systems as Sites of Surveillance, Control and Corporatization: A review of the critical literature. In: Society for Information Technology and Teacher Education International Conference. 2010. p. 252-257.

[6] Salimah, M.; Lim, S. H., Design of Personal Learning Environment Framework for Learner Autonomy. 4th International Conference on Computer Science and Information Technology (ICCSIT'2013). Dubai. 2013.

[7] Olivier, B.; Liber, O. Lifelong learning: The need for portable personal learning environments and supporting interoperability standards. Bristol: The JISC Centre for Educational Technology Interoperability Standards, Bolton Institute. 2001

[8] Downes, S., New Models of Open and Distributed Learning. In: Open Education: from OERs to MOOCs. Springer Berlin Heidelberg, 2017. p. 1-22.

[9] Commission of the European Communities (2001).

[10] Matthews, P., Informal Learning at Work: How to Boost Performance in Tough Times. Three Faces Publishing, 2013.

[11] Rogers, A., The base of the iceberg: Informal learning and its impact on formal and non-formal learning. Budrich, Barbara, 2014.

[12] Van Harmelen, M., Personal Learning Environments. In: ICALT. 2006. p. 815-816.

[13] Wheeler, S., Learning with'e's. Crown House Publishing, 2015.

[14] Black, P.; Wiliam, D. Developing the theory of formative assessment. Educational Assessment, Evaluation and Accountability (formerly: Journal of Personnel Evaluation in Education), v. 21, n. 1, p. 5-31, 2009.

[15] Yatian, C., Xiaomeng, L., Yufeng, J., \& Tongxiang, W. (2013, April). Research on learning-monitoring system for E-Learning. In Computer Science \& Education (ICCSE), 2013 8th International Conference on (pp. 1618). IEEE

[16] Melo Filho, I. J., Carvalho, R. S., Tavares, E. L. C., Gomes, A.S., Towards the Formative Accompaniment in E-Learning: Conception of a Social Mechanism Between the Educational Contexts LMS and PLE. In: E-LEARN 2014 - World Conference on E-Learning, 2014, New Orleans/United States. Proceedings of E-LEARN 2014 World Conference on E-Learning in Corporate, Government, Healthcare, and Higher Education 2014. New Orleans/Lousiana/USA: Association for the Advancement of Computing in Education (AACE), 2014. v. I. p. 13301339.

[17] Erl, T., SOA: Principles of service design. Pearson Prentice Hall, São Paulo, v. 200, p. 18-21, 2009.

[18] Wilson, S., Liber, O., Johnson, M., Beauvoir, P., Sharples, P., Milligan, C.: Personal Learning Environments: Challenging the dominant design of 
educational systems. Journal of e-Learning and Knowledge Society 3, 27-38. 2007.

[19] Melo Filho, I. J.; Gomes, A.S.; Korhonen, A., Exploring Possibilities for Teachers Accompany Learners Formatively in Vocational Education and Training (VET): Developing a Service between Educational Contexts LMS and PLE. In: 11th CSCL2015 Gothenburg/Sweden: International Society of the Learning Sciences (ISLS) \& University of Gothenburg, 2015.

[20] Stickdorn, M. Schneider; Schneider, J. J., (2014) This is Service Design Thinking: Basics, Tools, Cases. 